\title{
Pancreatic Elastase-1 Level in Older Individuals
}

Fawzy M. Khalil ${ }^{a}$, Sherif I. Negm ${ }^{a}$, Mohamed A. Elassal ${ }^{a}$, Walid Abdel Latif ${ }^{b}$, Amira K. ElAlfy $^{\mathrm{a}}$, Mohamed A. Afifi ${ }^{\mathrm{a}}$, Mohammed R. Refaey ${ }^{\mathrm{a}}$

${ }^{a}$ Department of Internal Medicine, Benha faculty of medicine, Banha University, Egypt. ${ }^{\mathrm{b}}$ Department of Clinical and Chemical Pathology, Benha faculty of medicine, Banha University, Egypt.

\section{Correspondence to:Mohammed} R. Refaey, Department of Internal Medicine, Benha faculty of medicine, Banha University, Egypt.

\section{Email:}

muslim_man89@yahoo.com

Received: 5 March 2020

Accepted: 15 May 2020

\begin{abstract}
:
Background: Disturbances in the endocrine pancreatic function increases with age, yet the deterioration of the exocrine gland has gained less attention. With aging, the incidence of maldigestive symptoms and malnutrition increases, raising the possibility that these might be caused at least in part by inadequate pancreatic enzyme secretion due to degenerative processes of the gland. Purpose: To investigate fecal elastase-1 (FE-1) levels among over 60 years old Egyptian individuals without known gastrointestinal disease or diabetes mellitus. Methodology: FE-1 was measured by ELISA in 45 subjects divided into a case group of 35 individuals who are old age in normal status without known gastrointestinal disease, prior gastrointestinal surgery or diabetes mellitus and another control group of 10 young healthy controls. Results: There was significant difference of FE-1 level between case and control groups with significant low median and range value of FE-1
\end{abstract} level in case group ,also there was significant relationship between FE-1 level and presence of dyspeptic symptoms in both case and control groups. Median and range value of FE-1 level in subjects having dyspeptic symptoms was low compared to those having no symptoms in case group. ROC curve analysis revealed that FE-1 cut off value <2.99 can be significant predictor for exocrine pancreatic insufficiency (EPI) with sensitivity $76.9 \%$ and specificity $77.3 \%$ and AUC 0.818 and $\mathrm{p}$ value 0.002. Conclusion: These results indicate that FE-1 level correlated negatively with age and has significant relationship with dyspeptic symptoms.

Keywords: dyspeptic symptoms, exocrine pancreatic insufficiency, fecal elastase-1, pancreatic function test. 



\section{Introduction}

Pancreas is a doubled-entity organ, with both an exocrine and an endocrine component, reciprocally interacting and closely cooperating for the digestion, absorption, and metabolism of oral nutrients [1]

It is well known that the incidence of disturbances in the endocrine pancreatic function increases with age, yet the deterioration of the exocrine gland has gained much less attention [2]

Reduction in exocrine secretion capacity leads to maldigestion of nutrients which might manifest as clinical symptoms like malnutrition, steatorrhoea, diarrhea, abdominal pain and weight loss. In addition, as the cause of abdominal pain remains unclear in about $30 \%$ of the cases, pancreatic insufficiency should be considered as a possible etiology in these situations [3].

The structural changes occurring in the pancreas as a part of the natural aging process include patchy fibrosis, lipomatosis, ductal epithelial hyperplasia, ductal widening and intraluminal protein deposition [4].
With aging, also the incidence of maldigestive symptoms and malnutrition increases, raising the possibility that these might be caused at least in part by inadequate pancreatic enzyme secretion due to degenerative processes and damage of the gland.

Since pancreatic elastase- 1 is very stable during intestinal transit and is enriched fiveto six fold in feces, it can be used in the assessment of the pancreatic exocrine secretory capacity [5].

\section{Purpose}

The aim of this study is to investigate the FE-1 levels among over 60 years old Egyptian individuals without known gastrointestinal disease or diabetes mellitus, as a method to assess pancreatic inadequate enzyme secretion due to degenerative processes of pancreas with aging.

\section{Materials and methods}

\section{Ethical approval}

The study protocol was approved by the faculty's ethical committee and written informed consent was obtained from all patients participating in this study after explaining the study measures in details. 


\section{Study design}

This observational cross sectional study was conducted on 45 subjects attending internal medicine outpatient clinic in Benha University Hospitals in the period from July 2018 to July 2019.

\section{Study population}

This study included 35 individuals of both sexes who are old age in normal status and 10 young healthy controls served as the control group.

None of the subjects had been diagnosed with exocrine pancreatic insufficiency or had been treated with pancreatic enzymes before the study.

\section{Inclusion Criteria:}

Over 60 years of age individuals, normal status and competence.

\section{Exclusion Criteria:}

Patients with diabetes mellitus or any known gastrointestinal disease and patients with prior gastrointestinal surgery.

\section{Investigations:}

-Samples of $1 \mathrm{~g}$ of stool from all subjects were collected and refrigerated at $-20 \mathrm{C}$
-The fecal elastase-1 level was measured by enzyme-linked immunosorbent assay in addition to abdominal ultrasonography and other laboratory tests: CBC, AST, ALT, Serum albumin, PT, Serum creatinine, FBS and $2 \mathrm{hr}$. PP blood sugar.

\section{Statistical analysis}

The collected data was revised, coded and tabulated using Statistical package for Social Science (IBM Corp. Released 2011. IBM SPSS Statistics for Windows, Version 20.0. Armonk, NY: IBM Corp.).Categorical data were presented as number and percentages while quantitative data were expressed as mean \pm standard deviation, Fisher-exact test (FET) was used to analyze categorical variables. Student " $\mathrm{t}$ " test was used to analyze normally distributed variables among 2 independent groups. While nonparametric variables were analyzed using Man Whitney U test (Z MWU). The ROC Curve (receiver operating characteristic) provides a useful way to evaluate the sensitivity and specificity for quantitative diagnostic measures that categorize cases into one of two groups. The optimum cut off point was defined as that which maximized the AUC value. The area under the ROC curve (AUC) results were considered excellent for AUC values > 0.9, very good 
for AUC values between 0.8-0.9, good for AUC values between 0.7-0.8, fair for AUC values between 0.5-0.69 and bad for AUC values $<0.5$.

\section{Results}

Comparison between case and control groups according to fecal elastase 1 level:

There was highly significant difference of fecal elastase 1 level between both case and control groups as median of fecal elastase 1 level in case group was $3.01 \mathrm{ng} / \mathrm{ml}$ while in control group was $3.56 \mathrm{ng} / \mathrm{ml}$. Table (1)\&Figure (1)

Fecal elastase 1 difference regarding dyspeptic symptoms:

There was significant relationship between fecal elastase 1 level and prescence of dyspeptic symptoms as median of fecal elastase 1 level in subjects with history of dyspeptic symptoms in case and control groups was (2.56 ng/ml, $2.78 \mathrm{ng} / \mathrm{ml})$ respectively, while in subjects without dyspeptic symptoms in case and control groups was $(3.14 \mathrm{ng} / \mathrm{ml}, 3.7 \mathrm{ng} / \mathrm{ml})$ respectively. Table (2)
Correlation between fecal elastase 1 and other variables:

In case group there was insignificant correlation of fecal elastase 1 with FBS, $2 \mathrm{~h}$ PP, AST, ALT, s. albumin, PT, s. creatinine , $\mathrm{Hb} \%$, TLC and Platelets count, meanwhile there was significant negative correlation between fecal elastase 1 level and age with $\mathrm{p}$ value (0.024). Table (3)

Fecal elastase difference regarding sex:

There was no a significant difference when comparing median fecal elastase 1 level between male and female subjects as median of fecal elastase 1 level in male and female subjects in case group was $(2.97 \mathrm{ng} / \mathrm{ml}, 3.09$ $\mathrm{ng} / \mathrm{ml}$ ) respectively, while median of fecal elastase 1 level in male and female subjects in control group was (4.43 ng/ml, 3.33 $\mathrm{ng} / \mathrm{ml}$ ) respectively. Table (4)

In the ROC curve:

Very good AUC for fecal elastase 1 (AUC = 0.818, $\mathrm{p}=0.002$ ). Best cut off value was $<2.99 \mathrm{ng} / \mathrm{mL}$ at which, sensitivity was 76.9, specificity was $77.3 \%$, PPV was $66.7 \%$, NPV was $85.0 \%$. Figure (2) \& Table (5) 

Table (1): Comparison between case and control groups according to fecal elastase 1 level.

\begin{tabular}{lcccc}
\hline & Case group (35) & Control group (10) & $\begin{array}{c}\text { Statistical test } \\
\text { (st t) }\end{array}$ & P value \\
\hline $\begin{array}{l}\text { Fecal elastase 1 (ng/ml) } \\
\text { Median (IQR) }\end{array}$ & $3.01(2.58-3.19)$ & $3.56(3.12-4.28)$ & MW $=2.89$ & $0.004 * *$ \\
\hline
\end{tabular}

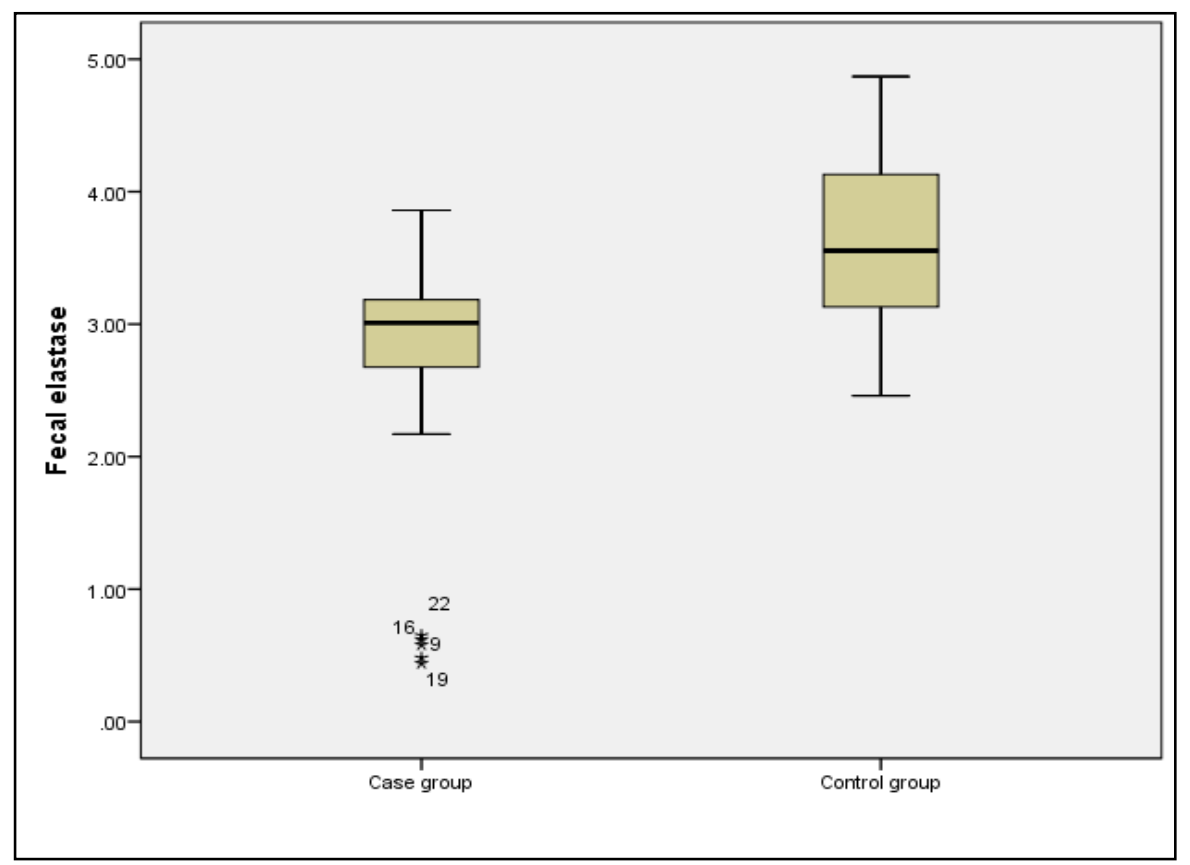

Figure (1): Box Wisker plot showing median and range of fecal elastase 1 level in case and control groups.

Table (2): Fecal elastase 1 difference regarding dyspeptic symptoms.

\begin{tabular}{lllll}
\hline $\begin{array}{l}\text { Fecal elastase } \\
\text { Median (IQR) }\end{array}$ & Positive dyspepsia & Negative dyspepsia & Statistial test & P value \\
\hline Case group (35) & $2.56(0.6-3.02)$ & $3.14(2.99-3.27)$ & MW=3.11 & $0.002^{* *}$ \\
Control group (10) & $2.78(2.46-3.09)$ & $3.7(3.25-4.58)$ & MW=2.09 & $0.037^{*}$ \\
\hline
\end{tabular}


Benha medical journal vol. 37, Special issue (Internal medicine and Hepatology), 2020

Table (3): Correlation between fecal elastase 1 and other variables among case group.

\begin{tabular}{lcc}
\hline Case group (35) & Statistical test (rho) & P value \\
Fecal elastase 1 & & \\
\hline Age & -0.38 & $0.024^{*}$ \\
FBS & -0.05 & 0.77 \\
2h PP & -0.17 & 0.32 \\
AST & -0.05 & 0.77 \\
ALT & -0.26 & 0.13 \\
Albumin & -0.21 & 0.22 \\
PT & 0.22 & 0.20 \\
Creatinine & -0.33 & 0.054 \\
Hb & 0.07 & 0.69 \\
TLC & 0.13 & 0.47 \\
Platelets & 0.09 & 0.63 \\
\hline
\end{tabular}

Table (4): Fecal elastase 1 difference regarding sex.

\begin{tabular}{lcccc}
\hline $\begin{array}{l}\text { Fecal elastase 1 } \\
\text { Median (IQR) }\end{array}$ & Male & Female & $\begin{array}{c}\text { Statistical } \\
\text { test }\end{array}$ & P value \\
\hline Case group (35) & $2.97(2.33-3.17)$ & $3.09(2.98-3.33)$ & MW= 1.52 & 0.128 \\
Control group (10) & $4.43(3.4-4.84)$ & $3.33(2.93-3.64)$ & MW=1.92 & 0.055 \\
\hline
\end{tabular}

Table (5): ROC curve analysis for fecal elastase 1 in case group.

\begin{tabular}{lcccc}
\hline Fecal elastase 1 & $\begin{array}{c}\text { Positive dyspepsia } \\
(\mathbf{1 3})\end{array}$ & $\begin{array}{c}\text { Negative dyspepsia } \\
\mathbf{( 2 2 )}\end{array}$ & $\begin{array}{c}\text { Statistical } \\
\text { test } \mathbf{( \mathbf { x } ^ { 2 } )}\end{array}$ & P value \\
\hline Positive $(<2.99)$ & $10(76.9)$ & $5(22.7)$ & 9.8 & $0.002^{* *}$ \\
Negative $(\geq 2.99)$ & $3(23.1)$ & $17(77.3)$ & & \\
AUC & & 0.818 & & \\
Cutoff point & & 2.99 & \\
Sensitivity & 76.9 & \\
Specificity & 77.3 & \\
PPV & & 66.7 & \\
NPV & 85.0 & \\
Accuracy & 77.1 & \\
\end{tabular}




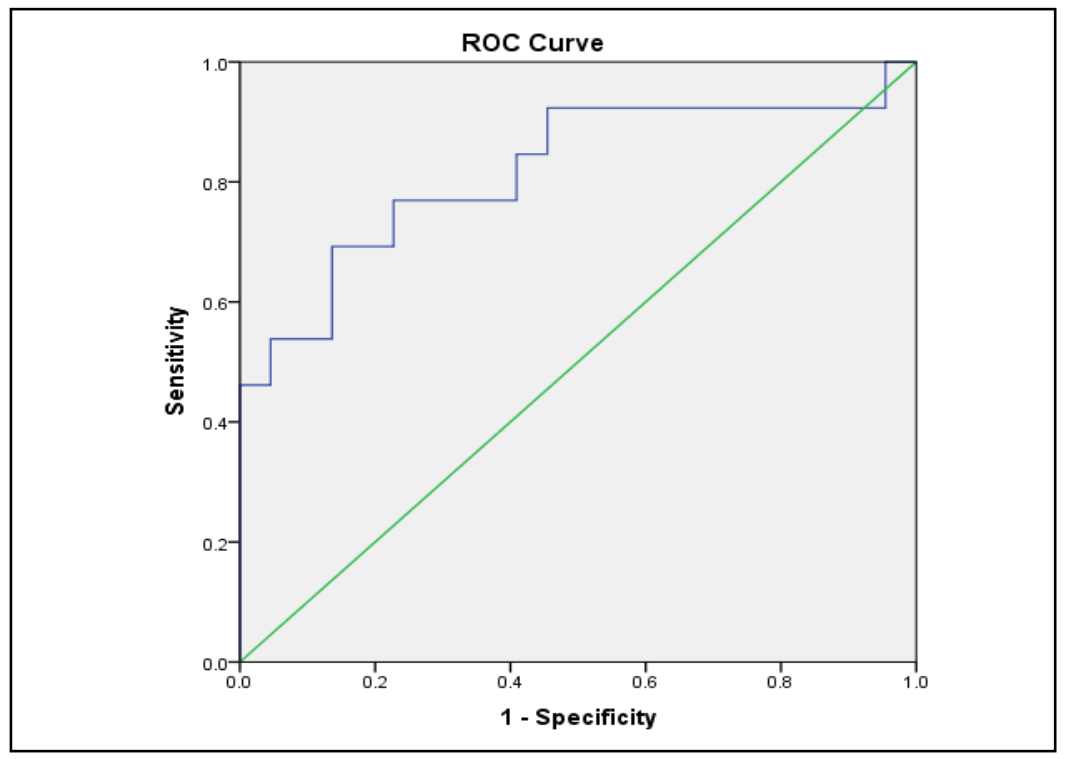

Figure (2): Validity of fecal elastase 1 level in detection of dyspepsia in case group

\section{Discussion}

Exocrine pancreatic insufficiency (EPI), an important cause of maldigestion and malabsorption, results from primary pancreatic diseases or secondarily impaired exocrine pancreatic function.

Pancreas undergoes various pathological changes with aging characterized by increased fatty replacement, fibrosis, lymphoplasmacytic infiltration, amyloid deposition, a decreased weight as well as development of intra-epithelial neoplastic changes [6].

Osteoporosis and osteomalacia become clinically conspicuous only after destruction of $90 \%$ of the pancreas. This means that early detection of exocrine and endocrine pancreas disorders is important for the prevention and early diagnosis and therapy of disorders based on pancreas insufficiency. It is therefore, recommended to analyze fecal pancreatic elastase 1 in risk patients regardless of whether there is a clinical sign of exocrine pancreas insufficiency or not. [7]

The enzyme pancreatic elastase 1 (ELA-1) is produced by the exocrine pancreas and secreted into the duodenum. Under physiological conditions, elastase 1 concentration of pancreatic juice is 170 $\mu \mathrm{g} / \mathrm{mL}$ - $360 \mu \mathrm{g} / \mathrm{mL}$. The enzyme is homogeneously distributed and concentrated five to six-fold in human faeces. It is 
excreted unmetabolised in faeces. The measurement of this proteolytic enzyme in stool by means of an enzyme-linked immunosorbent assay (ELISA) is a sensitive, specific, and relatively inexpensive non-invasive test. It shows higher sensitivity and specificity for exocrine pancreatic insufficiency than fecal chymotrypsin determination and is comparable to oral pancreatic function tests such as the pancreolauryl test.[8] The sensitivity of fecal elastase- 1 measurement in detecting severe exocrine insufficiency is excellent $(100 \%)$ in $[8 \& 9 \& 10$ ] and $(82 \%)$ in [11]. In contrast, its sensitivity in mild pancreatic insufficiency in different studies has been reported to be ranging from 16.7 to $65 \%$ [11 \& $12 \&$ 13]. Our study showed that aging has a significant impact on fecal elastase 1 level. This could be inferred from the following :

1. Highly significant difference of fecal elastase 1 level between both case and control groups. [table 1, fig 1].

2. Significant negative correlation between fecal elastase 1 level among case group and age. [table 3].

3. Fecal elastase 1 considered significant predictor for exocrine pancreatic function. [table 5].
4. Significant relationship between fecal elastase 1 level and prescence of dyspeptic symptoms. [table 2].

These results is in agreement with [2 ] who revealed that fecal elastase- 1 concentrations correlated negatively with age and $21.7 \%$ of subjects aged over 60 years without any known gastrointestinal diseases, gastrointestinal surgery or diabetes mellitus had fecal elastase-1 levels below $200 \mu \mathrm{g} / \mathrm{g}$ indicating pancreatic exocrine insufficiency. 14 Jreported that pancreatic exocrine function is impaired in healthy older individuals without any gastrointestinal disease. Five per cent of people older than 70 years and ten per cent older than 80 years have pancreatic exocrine insufficiency (PEI) with a faecal elastase-1 below $200 \mu \mathrm{g} / \mathrm{g}$ stool, and 5\% have severe PEI with faecal elastase-1 below $100 \mu \mathrm{g} / \mathrm{g}$ stool. This may lead to maldigestion and malnutrition. It was revealed that aging alters pancreatic secretion, through a decrease in flow rate, bicarbonate and enzyme secretion [15]. The relationship between aging and exocrine pancreatic function was studied by the secretin test which was recently standardized and revealed gradual decrease of enzyme output with aging [16 ] 
Strong evidence was provided for a marked functional involution of the exocrine pancreatic secretion during aging [17]

On the other hand :

It was found that only one of 68 subjects over 90 years old and none in their control group (mean age 52 years, range 21-81 years) had low fecal elastase-1 levels and there was no correlation between fecal elastase-1 and age [18]. It was concluded that the aging process per se does not significantly affect exocrine pancreatic function [ 19]. In our study, there was no significant difference when comparing median fecal elastase 1 level between male and female subjects [table 4].

But some researchers studied the secretory response of pancreas to secretin in healthy men and women below and over 45 years of age and no significant secretory differences were observed in the groups of younger males and females. When the over-45 groups of men and women were compared, the women exhibited a significant decrease in secretory response. [ 20]

\section{Conclusion}

The results of the study indicate that FE-1 level correlated negatively with age and has significant relationship with dyspeptic symptoms.

\section{References}

1. Pieler $T$, Chen $Y$. Forgotten and novel aspects in pancreas development. Biology of the Cell. 2006 Feb; 98(2):79-88

2- Herzig KH, Purhonen AK, Räsänen KM, Idziak J, Juvonen P, Phillps $R$, et al. Fecal pancreatic elastase-1 levels in older individuals without known gastrointestinal diseases or diabetes mellitus. BMC geriatrics. 2011 Dec; 11(1):4.

3- Talley NJ, O'Keefe EA, Zinsmeister AR, Melton III LJ. Prevalence of gastrointestinal symptoms in the elderly: a population-based study. Gastroenterology. 1992 Mar 1; 102(3):895-901.

4- Detlefsen S, Sipos B, Feyerabend B, Klöppel $G$. Pancreatic fibrosis associated with age and ductal papillary hyperplasia. Virchows Archiv. 2005 Nov 1; 447(5):800-5.

5- Walkowiak J, Nousia-Arvanitakis S, Agguridaki C, Fotoulaki M, Strzykala K, Balassopoulou A, et al. Longitudinal follow-up of exocrine pancreatic function in pancreatic sufficient cystic fibrosis patients using the fecal elastase-1 test. Journal of pediatric gastroenterology and nutrition. 2003 Apr 1; 36(4):474-8.

6- Matsuda Y, Tanaka M, Sawabe M, Mori S, Muramatsu M, Mieno MN, et al. Relationship between pancreatic intraepithelial neoplasias, pancreatic ductal adenocarcinomas, and single nucleotide polymorphisms in autopsied elderly patients. Genes, Chromosomes and Cancer. 2018 Jan; 57(1):12-8. 
7- Hardt PD, Krauss A, Bretz L, PorschOezcueruemez M, Schnell-Kretschmer H, Mäser $E$, et al. Pancreatic exocrine function in patients with type 1 and type 2 diabetes mellitus. Acta diabetologica. 2000 Dec 1; 37(3):105-10.

8- Löser CH, Möllgaard A, Fölsch UR. Faecal elastase 1: a novel, highly sensitive and specific tubeless pancreatic function test. Gut. 1996 Oct 1; 39(4):580-6.

9- Lüth $S$, Teyssen $S$, Forssmann $K$, Kölbel $C$, Krummenauer F, Singer MV. Fecal elastase-1 determination:? gold standard? Of indirect pancreatic function tests?. Scandinavian journal of gastroenterology. 2001 Jan 1; 36(10):1092-9.

10- Gullo L, Ventrucci M, Tomassetti $P$, Migliori $M$, Pezzilli $R$. Fecal elastase 1 determination in chronic pancreatitis. Digestive diseases and sciences. 1999 Jan 1; 44(1):210-3.

11- Lankisch PG, Schmidt I, König H, Lehnick $D$, Knollmann $R$, Löhr $M$, et al. Faecal elastase 1: not helpful in diagnosing chronic pancreatitis associated with mild to moderate exocrine pancreatic insufficiency. Gut. 1998 Apr 1; 42(4):551-4.

12- Naruse S, Ishiguro H, Ko SB, Yoshikawa T, Yamamoto T, Yamamoto A, et al. Fecal pancreatic elastase: a reproducible marker for severe exocrine pancreatic insufficiency. Journal of gastroenterology. 2006 Sep 1; 41(9):901-8.

13- Glasbrenner B, Schön A, Klatt S, Beckh K, Adler $G$. Clinical evaluation of the faecal elastase test in the diagnosis and staging of chronic pancreatitis. European journal of gastroenterology \& hepatology. 1996 Nov; 8(11):1117-20.
14- Löhr JM, Panic N, Vujasinovic M, Verbeke $C S$. The ageing pancreas: a systematic review of the evidence and analysis of the consequences. Journal of internal medicine. 2018 May; 283(5):446-60.

15- Laugier $R$, Bernard JP, Berthezene $P$, Dupuy $P$. Changes in pancreatic exocrine secretion with age: pancreatic exocrine secretion does decrease in the elderly. Digestion. 1991; 50(3-4):202-11.

16- Ishibashi T, Matsumoto S, Harada H, Ochi $K$, Tanaka J, Seno T, et al. Aging and exocrine pancreatic function evaluated by the recently standardized secretin test. Nihon Ronen Igakkai zasshi. Japanese journal of geriatrics. 1991 Sep; 28(5):599-605.

17- Vellas B, Balas D, Moreau J, Bouisson M, Senegas-Balas $F$, Guidet $M$, et al. Exocrine pancreatic secretion in the elderly. International journal of pancreatology. 1988 Dec 1; 3(6):497502.

18- Gullo L, Simoni P, Migliori M, Lucrezio L, Bassi M, Frau F, et al. A study of pancreatic function among subjects over ninety years of age. Pancreatology. 2009 May 1; 9(3):240-4.

19- Gullo L, Ventrucci M, Naldoni P, Pezzilli R. Aging and exocrine pancreatic function. Journal of the American Geriatrics Society. 1986 Nov; 34(11):790-2.

20- Tiscornia OM, Cresta MA, de Lehmann ES, Celener D, Dreiling DA. Effects of sex and age on pancreatic secretion. International Journal of Pancreatology. 1986 Jul 1; 1(2):95-118.

To cite this article: Fawzy M. Khalil, Sherif I. Negm, Mohamed A. Elassal, Walid Abdel Latif, Amira K. ElAlfy, Mohamed A. Afifi, Mohammed R. RefaeyPancreatic elastase-1 level in older individuals, BMFJ 2020; 37 (Internal medicine and Hepatology): 81-90. DOI: $10.21608 /$ bmfj.2020.24983.1227 